\title{
Commentary: To wrap or not to wrap-Have we now come full circle?
}

Jan D. Galla, MD, PhD

\author{
From Englewood Cardiac Surgery Associates, Englewood Hospital Medical Center, Englewood, NJ. \\ Disclosures: Author has nothing to disclose with regard to commercial support. \\ Received for publication Jan 7, 2019; accepted for publication Jan 8, 2019; available ahead of print Feb 13, 2019 \\ Address for reprints: Jan D. Galla, MD, PhD, Englewood Cardiac Surgery Associates, 350 Engle St, Suite 5200, \\ Englewood, NJ 07631 (E-mail: Jan.Galla@ehmchealth.org). \\ J Thorac Cardiovasc Surg 2019;158:1315-6 \\ $0022-5223 / \$ 36.00$ \\ Copyright (C) 2019 by The American Association for Thoracic Surgery \\ https://doi.org/10.1016/j.jtcvs.2019.01.028
}

Aortic dissection: The term strikes terror into the hearts of many outside our specialty, with whispered mortalities of $1 \%$ to $2 \%$ /hour or $15 \%$ to $18 \%$ mortality at surgery. The development of surgical approaches to the management of aortic dissection has in many ways closely followed that of surgery of the aortic root: Early efforts were plagued with excessive bleeding, and not until the inclusion technique reported by Bentall and DeBono ${ }^{1}$ were outcomes more universally successful. The "button" described by Kouchoukos and colleagues ${ }^{2}$ alleviated the major complication associated with the inclusion technique (pseudoaneurysm formation), allowed complete replacement of the root and ascending aorta, and made treating these patients more routine with acceptable outcomes. Nonetheless, complications of the repairs remain confounding. Among the most humbling of these complications is bleeding, which has been reported in as many as $28 \%$ of selected patient subsets. In this issue of the Journal, Zhang and colleagues ${ }^{3}$ report on their experience with a modified Cabrol fistula that reduces this figure to $0 \%$.

The Cabrol fistula (or shunt) is a periaorta-to-right atrial fistula created to direct any bleeding from the repair into the right atrium, thereby both preventing tamponade and diminishing the operative duration. First described in $1986,{ }^{4}$ the technique has undergone many modifications, all of which require obliteration of any egress points (eg, transverse sinus) from which free blood might escape into the pericardium. Creation of this closed space is difficult in the virgin pericardium once the aortic repair has been effected, but Zhang and colleagues ${ }^{3}$ avoid this difficulty by creating the posterior closure before undertaking the aortic repair, whether primarily or with a piece of bovine pericardium. After completion of the aortic repair and control of any major (spurting) bleeding, the periaortic "sac" is completed by suturing another piece of bovine pericardium over the anterior structures. Before completion of the repair, a small defect is created in the right atrium or medial superior vena cava, and the anterior baffle is completed.

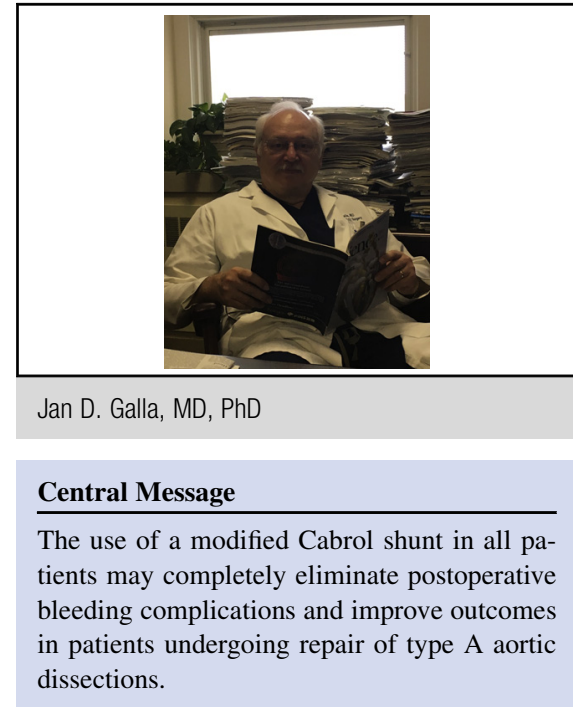

See Article page 1307.
Direct comparison of shunt and nonshunt groups was undertaken: Group sizes and characteristics were essentially identical, and all surgeries were performed by the same surgeon. Interestingly, the decision to shunt or not to shunt was made by a second surgeon; Zhang and colleagues ${ }^{3}$ do not elaborate as to why. Comparison of the 2 groups' outcomes demonstrated statistically significant improvements in chest tube drainage, reexploration for bleeding, blood transfusions, intensive care unit stay, and dialysis need. A trend toward decreased length of ventilator support was seen but did not reach significance. A metric labeled "chest closure time" was also significantly decreased, although the term is not defined. Zhang and colleagues ${ }^{3}$ note that closure of the transverse sinus only requires 1 to 2 minutes, although time to create the completed fistula was not studied. In addition, no episodes of postoperative heart failure from shunt flow were seen, and all fistulas spontaneously closed although the methods used to determine this are not specified.

The potential to offer a type A dissection repair without any risk of reexploration for bleeding is enticing, although one questions whether the need to add a supplemental procedure for all patients is justified. Despite the historical reports of high "take-back" rates, ${ }^{5-7}$ with meticulous care and precise technique, reoperative rates of $2 \%$ to $4 \%$ are 
increasingly reported. ${ }^{8,9}$ Although accurate assessments of postoperative reexploration rates are difficult to ascertain (most type A series do not report bleeding rates), and the present series results remain to be replicated (or even extended), one is compelled to question whether the placing of an additional piece of foreign material in every patient is justified and what, if any, long term sequelae of fistula formation exist. Indeed, one may also reasonably question whether the shunt actually functions as such or spontaneously closes after heparin reversal.

Zhang and colleagues ${ }^{3}$ have presented an intriguing solution to a frustrating problem associated with dissection repairs. Further evaluation of their results seems to be ongoing, and studies by others may confirm these findings. It may ultimately be that wrapping the repair, albeit in a larger baggie than originally described, may return us to the early days of dissection and root repairs.

\section{References}

1. Bentall H, DeBono A. A technique for complete replacement of the ascending aorta. Thorax. 1968;23:338-9.
2. Kouchoukos NT, Karp RB, Blackstone EH, Kirklin JW, Pacifico AD, Zorn GL. Replacement of the ascending aorta and aortic valve with a composite graft. Results in 86 patients. Ann Surg. 1980;192:403-13.

3. Zhang H, Wu X, Fang G, Qui Z, Chen L-w. Is it justified to apply a modified Cabrol fistula in surgical repair of acute type A aortic dissection? J Thorac Cardiovasc Surg. 2019;158:1307-14.e2

4. Cabrol C, Pavie A, Mesnildrey P, Gandjbakhch I, Laughlin L, Bors V, et al. Longterm results with total replacement of the ascending aorta and reimplantation of the coronary arteries. J Thorac Cardovasc Surg. 1986;91:17-25.

5. Conway BD, Stamou SC, Kouchoukos NT, Lobdell KW, Khabbaz KR, Murphy E, et al. Improved clinical outcomes and survival following repair of acute type A aortic dissection in the current era. Interactive Cardiovasc Thorac Surg. 2014; 19:971-7.

6. Zindovic I, Gudbjartsson T, Ahlsson A, Fuglsang S, Gunn J, Hansson EC, et al. Malperfusion in acute type A aortic dissection: an update from the Nordic consortium for acute type A aortic dissection. J Thorac Cardiovasc Surg. 2019;157: 1324-33.e6.

7. Kreibich M, Bavaria JE, Branchetti E, Brown CR, Chen Z, Khurshan F, et al. Management of patients with coronary artery malperfusion secondary to type A aortic dissection. Ann Thorac Surg. November 13, 2018 [Epub ahead of print].

8. Etz CD, Bischoff MS, Bodian C, Roder F, Brenner R, Griepp RB, et al. The Bentall procedure: is it the gold standard? A series of 597 consecutive cases. J Thorac Cardiovasc Surg. 2010;140(6 Suppl):S64-70; discussion S86-91.

9. Andersen ND, Ganapathi AM, Hanna JM, Williams JB, Gaca JG, Hughes GC. Outcomes of acute type A dissection repair before and after implementation of a multidisciplinary thoracic aortic surgery program. J Am Coll Cardiol. 2014; 63:1796-803. 